\title{
Enhanced silver diamine fluoride therapy using the PILP method -A nanoindentation study
}

\author{
Hamid NURROHMAN ${ }^{1,2}$, Stefan HABELITZ², Kuniko SAEKI ${ }^{2}$, Alireza SADR ${ }^{3}$, Laurie B. GOWER \\ Vanessa PAZDERNIK ${ }^{5}$, Junji TAGAMI ${ }^{6}$, Sally J. MARSHALL ${ }^{2}$ and Grayson W. MARSHALL ${ }^{2}$ \\ ${ }^{1}$ Missouri School of Dentistry and Oral Health, A.T. Still University, 800 W. Jefferson St. Kirksville, MO, 63501, USA \\ ${ }^{2}$ Department of Preventive and Restorative Dental Sciences, University of California San Francisco, 707 Parnassus Ave., Suite D-4000 San \\ Francisco, CA, 94143, USA \\ ${ }^{3}$ Biomimetics Biomaterials Biophotonics \& Technology Laboratory, Department of Restorative Dentistry, University of Washington School of Dentistry, \\ 1959 NE Pacific St. Box 357456, Seatle, WA, 98195-7456, USA \\ ${ }^{4}$ Materials Science and Engineering Department, University of Florida, Rhines Hall, Gainesville, FL, 32603, USA \\ ${ }^{5}$ Department of Research Support, A. T. Still University, 800 W. Jefferson St. Kirksville, MO, 63501, USA \\ ${ }^{6}$ Department of Cariology and Operative Dentistry, Graduate School of Medical and Dental Sciences, Tokyo Medical and Dental University, 1-5-45, \\ Yushima, Bunkyo-ku, Tokyo 113-8549, Japan \\ Corresponding author, Hamid NURROHMAN; E-mail: hnurrohman@atsu.edu, h.nurrohman@gmail.com
}

The aim of this study was to evaluate the feasibility of applying the polymer-induced liquid-precursor (PILP) method to enhance silver diamine fluoride (SDF) therapy. One hundred forty micrometer deep artificial caries lesions were treated with (A) 38\% SDF solution and (B) 38\% SDF containing poly-L-aspartic acid (pASP). Changes in the nanomechanical profile across the lesion were evaluated. Hydrated artificial lesions had a low reduced elastic modulus $(0.3 \mathrm{GPa})$ and nanohardness $(0.02 \mathrm{GPa})$ region extending about $100 \mu \mathrm{m}$ into the lesion, with a gradual linear increase to about $168 \mu \mathrm{m}$ where the values plateaued to around $18 \mathrm{GPa} / 1.0$ GPa. Topical application of SDF resulted in significantly recovered properties $(p<0.001)$. SDF containing pASP resulted in greater nanomechanical properties compared to SDF alone, showing similar sloped regions up to $96 \mu \mathrm{m}$, then SDF alone dropped while SDF containing pASP continued at a modest slope until reaching normal at $144 \mu \mathrm{m}$. This nanoindentation study shows enhanced SDF therapy using the PILP method.

Keywords: Silver diamine fluoride, Artificial caries dentin lesion, Polymer-induced liquid-precursor, Caries arrest, Nanomechanical recovery

\section{INTRODUCTION}

Dental caries continue to be a highly prevalent global disease. Dental caries can be defined as a bacterial disease of the calcified tissues of teeth. Acid-producing bacteria feed on fermentable carbohydrates and produce organic acids as byproducts. The acids dissolve calcium and phosphate minerals, leading to caries lesions. As the carious lesion progresses into dentin, activation of endogenous bound protease leads to the degradation of collagen fibrils and further decrease in the mechanical properties of dentin ${ }^{1-3)}$.

Traditional approaches of treating dentin caries requires mechanical removal of the infected dentin tissue with hand instruments or powered dental drills. Tooth structure lost during removal of the decayed lesion is restored with dental fillings or full coverage crowns. Non-invasive, interim interventions for arresting dental caries have been needed, especially in underserved populations lacking timely access to restorative dental services. Such an intervention, silver diamine fluoride (SDF), has been used internationally for decades to halt the dental caries process by killing bacteria, along with the deposition of a "black crust," generating a sclerotic

Color figures can be viewed in the online issue, which is available at J-STAGE.

Received Aug 24, 2019: Accepted Dec 11, 2019

doi:10.4012/dmj.2019-273 JOI JST.JSTAGE/dmj/2019-273 protective coating of secondary dentin ${ }^{4}$. However, clinical trials that reported remineralization kinetics found that the arrested lesions are limited to the outer layer, while the deeper dentin lesion appears to be less affected ${ }^{5}$. Despite the positive anti-caries performance of SDF, there are few rigorous studies of SDF penetration depth and enhancement. Thus, there is a need for a modified strategy that promotes additional lesion penetration and distribution of the SDF treatment.

A biomimetic remineralization process, the so-called polymer-induced liquid-precursor (PILP) process, which imitates the natural remineralization process, appears to be a suitable method to reintroduce mineral into extra- and intrafibrillar collagen fibrils, thereby leading to nanomechanically and functionally recovered tissue properties $^{6,7)}$. The biomimetic PILP process consists of anionic macromolecules such as poly-L-aspartic acid (pASP), a simple mimic for the acidic or phosphorylated non-collagenous proteins found in hard tissues ${ }^{8-10)}$. PILP stabilizes a supersaturated mineralization solution by interacting with calcium and phosphate ion clusters to form nano-droplets of a hydrated amorphous mineral precursor of about $10-20 \mathrm{~nm}$ in diameter ${ }^{11}$. These nanodroplets are considered a precursor to the crystalline mineral and are able to unload the ion content into the interstices of collagen fibrils to create 
intrafibrillar amorphous calcium phosphate (ACP). Over a period of days, ACP transforms into aligned apatite nanocrystallites oriented with their [001] axes parallel to the fibrils, similar to the nanocrystals observed in mineralized tissues like bone, dentin and cementum ${ }^{11}$. In our recent study ${ }^{12)}$, fluoride was successfully incorporated into the PILP-mineralization of Type I collagen, resulting in collagen-mineral composite systems containing both hydroxyapatite and fluorapatite. Although high concentrations of fluoride were disruptive to the PILP process, at the lower concentrations there was a good balance between intra- and extra-fibrillar mineral; thus, it seemed reasonable to incorporate pASP as required for inducing the PILP process to SDF solution.

In this study, we report on the design of biomimetic SDF that contains pASP that is applied to artificial lesions in dentin. It was hypothesized that combination of SDF and pASP can enhance penetration and distribution of mineral, leading to the nanomechanical recovery of artificial dentin lesion. The nanomechanical properties of demineralized dentin lesion were examined by nanoindentation to measure the change in elastic modulus and nanohardness.

\section{MATERIALS AND METHODS}

\section{Tooth preparation}

The study was reviewed by the ATSU institutional review board and was considered exempt under CFR Section: 45CFR46.101 (b) (4). Permanent, fully-formed human third molars were obtained from the UCSF dental hard tissue specimen core according to the approved protocols. Teeth were sterilized by gamma radiation, which did not affect their mechanical properties ${ }^{13)}$, and stored in deionized water at $4^{\circ} \mathrm{C}$ until prepared. Dentin blocks measuring 6 (length) $\times 3$ (width) $\times 2.5$ (height) $(\mathrm{mm})$ were cut from the mid-coronal region of the selected teeth perpendicular to the tubule direction. The sample surfaces were ground with $\mathrm{SiC}$ abrasive papers from 320 to 1200 grit, and then polished with aqueous diamond suspensions (Buehler, Lake Bluff, IL, USA) of 3.0, 1.0, and $0.25 \mu \mathrm{m}$ particle sizes. Each sample surface was sealed with nail varnish (Revlon, New York, NY, USA) except for a $3 \times 3-\mathrm{mm}$ window to prevent demineralization (Fig. 1).

\section{Artificial caries lesion formation and SDF topical treatment}

A demineralization buffer containing $2.2 \mathrm{mM}$ calcium phosphate and $0.05 \mathrm{M}$ acetic acid, $\mathrm{pH}$ adjusted to 5.0, was used to create artificial caries lesions similar to those reported previously ${ }^{6,14)}$. Each nail varnish-coated dentin block was placed in a $50 \mathrm{~mL}$ tube with $40 \mathrm{~mL}$ of the buffer (Fig. 1). Demineralization time was calculated from the kinetics curve obtained from a previous study ${ }^{15}$, $66 \mathrm{~h}$ for acetate buffer to create lesions with a target depth of approximately $140 \mu \mathrm{m}$, characterized by a severely demineralized outer zone and a transition zone with increasing properties that are similar to natural caries lesions ${ }^{16,17)}$. After demineralization, samples were harvested, rinsed thoroughly with de-ionized water, and stored in $100 \%$ humidity to maintain hydration until studied.

Sample size and power analysis were based on calculations from a previous study ${ }^{6}$. For this study, we used 5 teeth per group which has $92 \%$ power to detect an effect size of 1.0 in a design with 35 repeated measurements having intra-sample correlation of 0.2 and 0.05 alpha level. Prepared demineralized dentin blocks were randomly divided into 3 groups as noted in Fig. 1. Group 1 (DEM) served as a control group and did not receive any SDF topical treatment and represented untreated artificial caries-like dentin lesions. Groups 2 (DEM-SDF) and 3 (DEM-SDF+pASP) were treated with

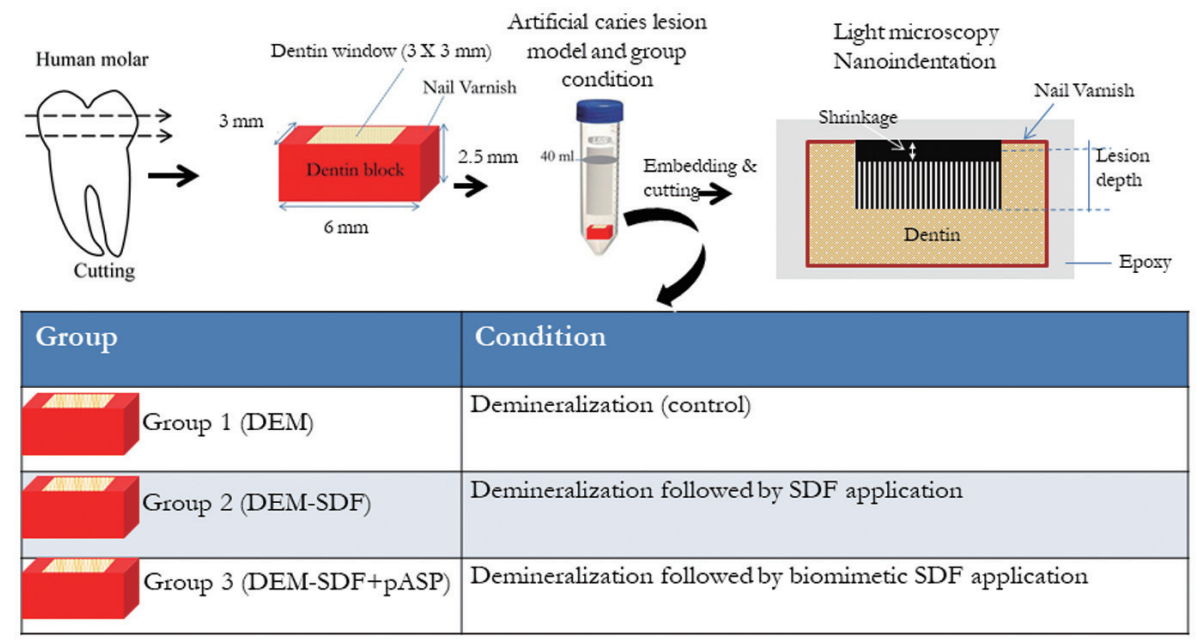

Fig. 1 Schematic drawing for the specimen preparation, artificial caries lesion model, group condition, visualization under the light microscopy observation and nanoindentation analysis. 
commercially available SDF solution at 38\% (Advantage Arrest, Elevate Oral Care, West Palm Beach, FL, USA). The 38\% SDF solution containing pASP (DEM$\mathrm{SDF}+\mathrm{pASP}$ ) was applied on demineralized dentin block with a microbrush and allowed to absorb for $1 \mathrm{~min}$. Excess was removed and rinsed with water. The first modified SDF, 1-drop ( $22 \mu \mathrm{L})$ solution was created by dissolving $100 \mu \mathrm{g} / \mathrm{mL}$ of pASP with a molecular weight of $27 \mathrm{kDa}$ (Alamanda polymers, Huntsville, AL, USA). This DEM-SDF+pASP solution (referred to "biomimetic SDF" in the current study) was stable and showed no evidence of precipitation during use. One drop of biomimetic SDF was used to treat only 1 lesion, keeping the same pASP concentration $(100 \mu \mathrm{g} / \mathrm{mL})$ in SDF solution. The 3 groups did not receive any remineralization treatment such as artificial saliva or simulated body fluid; therefore, the results would show the immediate effects of the treatment on arresting caries at baseline.

\section{Shrinkage of lesions and nanomechanical recovery evaluation}

The blocks containing the lesions were embedded at room temperature in epoxy (Epoxicure, Buehler). After embedding, each block was cut perpendicular to the surface to expose the lesion structure from the most demineralized outer portion through the lesion and into sound dentin using a low speed water-cooled diamond saw (Isomet, Buehler). The cross sections (minimum thickness of $400 \mu \mathrm{m}$ ) were fixed to metal discs (Ted Pella, Redding, CA, USA) using a cyanoacrylate adhesive (QX-4, MDS Products, Laguna Hills, CA, USA) and prepared for nanoindentation by polishing as described above and hydrated in de-ionized water for one hour before measurements started. The specimens were examined in an optical microscope (Olympus CX33, Tokyo, Japan) to determine the amount of shrinkage that occurred when the specimen was dehydrated during embedding and the demineralized zone collapsed in areas of insufficient mineralization with reference to the adjacent normal dentin. This procedure has been used extensively as an early indicator of remineralization ${ }^{6,7}$. The individual shrinkage values for each sample were measured in cross sections with depth defined as the distance from surface of the normal dentin to the surface of the treated zone, which provided a corrected location for the starting surface position elastic modulus and hardness plots obtained by nanoindentation (Fig. 1).

Nanoindentation (G200, Agilent Technologies, Santa Clara, CA, USA) was used for nanomechanical property testing and performed in a liquid cell filled with deionized water. A sharp diamond Berkovich indenter was used and calibrated with a fused-silica sample prior to evaluation. Site-specific measurements of reduced elastic modulus $\left(\mathrm{E}_{\mathrm{R}}\right)$ and nanohardness $(\mathrm{H})$ were made using a maximum force of $10 \mathrm{gf}(0.098 \mathrm{~N})$ with time to load of $15-$ $26 \mathrm{~s}$ (loading and unloading) as previously reported ${ }^{18)}$. Indentations were made at intervals of $4 \mu \mathrm{m}$ starting from the most demineralized outer surface of the lesion and proceeding inwards through the depth of the lesion and into sound dentin, covering a total distance of $200 \mu \mathrm{m}$.
Two similar lines of indents were made in each sample. The data was recorded and processed by Testworks 4 software (MTS Systems, Eden Prairie, MN, USA). The changes in nanomechanical properties influenced by SDF topical treatment in presence or absence of pASP were analyzed following the detailed procedure of our previous studies ${ }^{6,7)}$. Semi-parametric regression models were used to estimate mean $\mathrm{E}_{\mathrm{R}}$ and $\mathrm{H}$ across depth for each group to provide a flexible, non-linear framework. The smoothing method we chose, penalized linear splines, retains a relatively large number of knots but constrains their influence and has a straightforward extension to the longitudinal setting. We allowed the degree of smoothing and heteroskedasticity to vary by group. A random intercept and slope also allowed for the magnitude of the correlation among repeated measures on the same sample to depend on the depth separating them ${ }^{19)}$. From the fitted spline, three breakpoints were estimated ${ }^{20)}$. The sample-averages with fitted group splines, breakpoints, and corresponding $95 \%$ pointwise confidence interval (CI) were plotted. Non-overlapping CIs indicate significant differences between the groups at the timepoint $(p<0.05)$. Area under the curve (AUC; $\mathrm{GPa}-\mu \mathrm{m}$ ) of $\mathrm{E}_{\mathrm{R}}$ and $\mathrm{H}$ versus depth (in $4 \mu \mathrm{m}$ intervals) were approximated for each line within a sample in both the outer lesion (64 to $140 \mu \mathrm{m}$ ), and inner lesion (140 to $200 \mu \mathrm{m})$ depths. Mixed effects models using AUC as the dependent variable, were used to determine differences in AUC between groups and lesion depths. We used Tukey adjustment for multiple comparisons. Random line and sample effects allowed for correlation among repeated measures across lesion depths on the same line and further across different lines on the same sample. Bayesian information criterion (BIC) informed the structure of the residual variance where a unique treatment and depth variance were allowed for $\mathrm{E}_{\mathrm{R}}$ and $\mathrm{H}$, respectively. We report means, standard deviations (SD), and $95 \%$ CI. SAS version 9.4 software (SAS Institute, Cary, NC, USA) and R version 3.5.2 software (Vienna, Austria) were used to conduct the analyses.

\section{RESULTS}

\section{Optical microscopy and shrinkage analysis}

Dehydration of demineralized dentin leads to a collapse of the collagenous matrix when not supported by apatite mineral or absorbed water ${ }^{6,21}$. This collapse was visualized on cross sections through the artificial lesions and quantified as the distance from the normal dentin surface to the surface of the collapsed demineralized zone as shown in Fig 2. We have shown previously that after $66 \mathrm{~h}$ of demineralization a total lesion depth of about 140 $\mu \mathrm{m}$ is reached in dentin ${ }^{7}$. This leads to shrinkage of the demineralized zone of $\sim 64 \mu \mathrm{m}$ upon drying (Fig. 2A).

Light microscopy of sectioned SDF-treated artificial caries lesions showed black-brown stains where SDF was absorbed and oxidized (Fig. 2B), and its penetration into the lesion depths could be seen as elongated striations with gradient density, matching the orientation of the dentinal tubules. It is interesting to note that 

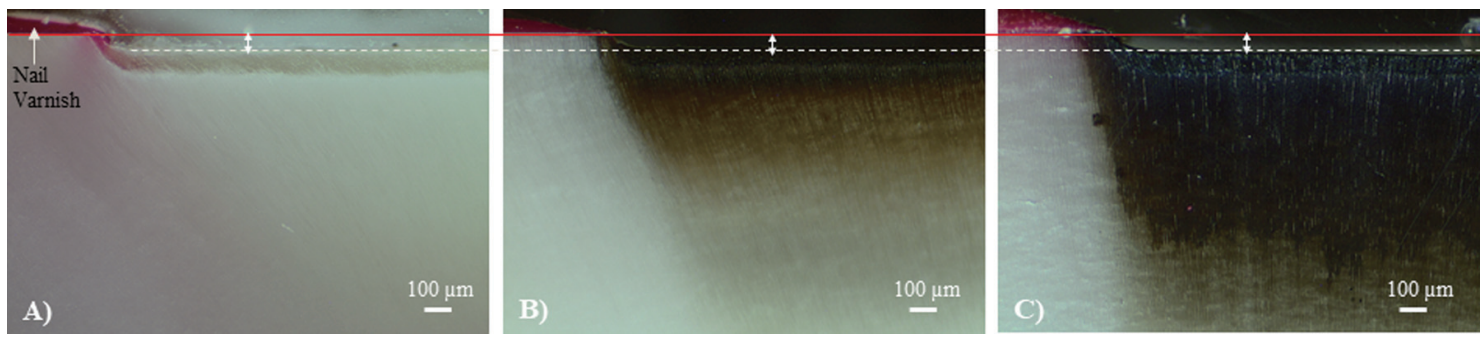

Fig. 2 Optical micrographs of dried cross sections to measure shrinkage of the lesion depths.

A) demineralized lesion (DEM) with nail varnish shown protecting the unexposed surface; B) After treatment, shrinkage was similar for both B) DEM-SDF and C) DEM-SDF+pASP. Artificial caries lesion treated with SDF shows black and brown stains formed in situ further into lesion depth. The biomimetic SDF-pASP shows intense staining far greater into the tooth than SDF alone. Solid red line $=$ original surface location, white dotted line=lesion depth, double headed arrow $=$ shrinkage.

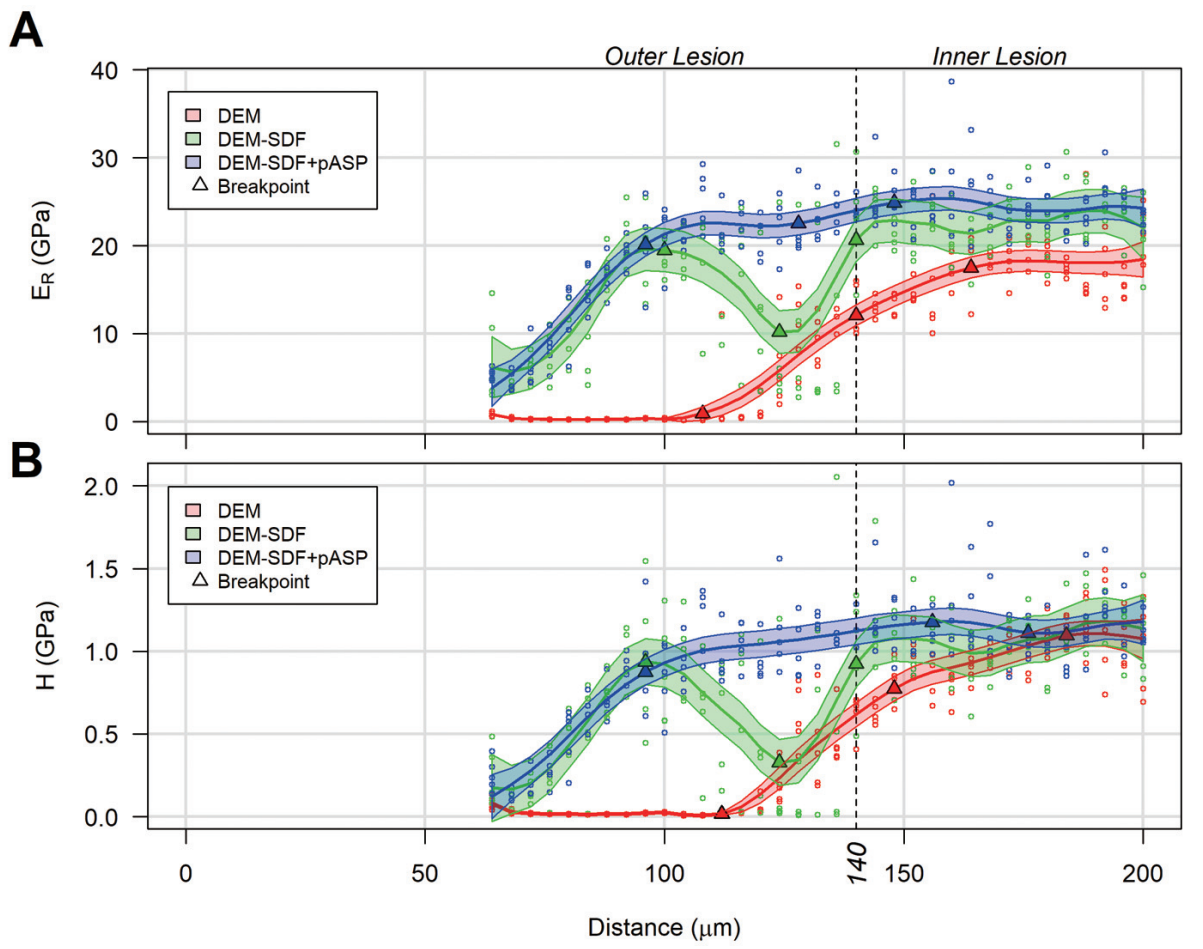

Fig. 3 Depth plots, with joined line segments for sample-average measurements, and fitted penalized linear splines with 95\% pointwise CI for (A) elastic modulus, $\mathrm{E}_{\mathrm{R}}$, and (B) nanohardness, H. Penalized linear splines are a class of semiparametric regression models which fit a smooth curve by retaining a relatively large number of knots but constraining their influence. Three breakpoints were estimated on each spline.

structures of more intense uniform coal-black staining formed throughout the lesion and then further into the normal dentin when SDF+pASP was applied to caries lesions (Fig. 2C). However, these visible dark striated stains were not a result of shrinkage changes from the demineralized dentin control, which were similar for both DEM-SDF and DEM-SDF+pASP (Figs. 2B-C).

\section{Nanoindentation}

Discrete nanoindentations were performed on cross sections along lines across fully hydrated lesions for the DEM group and after DEM and SDF topical treatments for the SDF and SDF+pASP groups. Figure 3 shows mean values of the reduced $\mathrm{E}_{\mathrm{R}}$ and $\mathrm{H}$ versus depth, or distance from the lesion surface. For DEM, accounting for shrinkage, a zone of very low elastic modulus and nanohardness $\left(\mathrm{E}_{\mathrm{R}}=0.3 \mathrm{GPa} ; \mathrm{H}=0.02 \mathrm{GPa}\right)$ was observed to a depth of about 100 to $112 \mu \mathrm{m}$ in demineralized lesions followed by a gradual linear increase that reached normal dentin $\left(\mathrm{E}_{\mathrm{R}}=18 \mathrm{GPa} ; \mathrm{H}=1.0 \mathrm{GPa}\right)$ at a depth of 
A

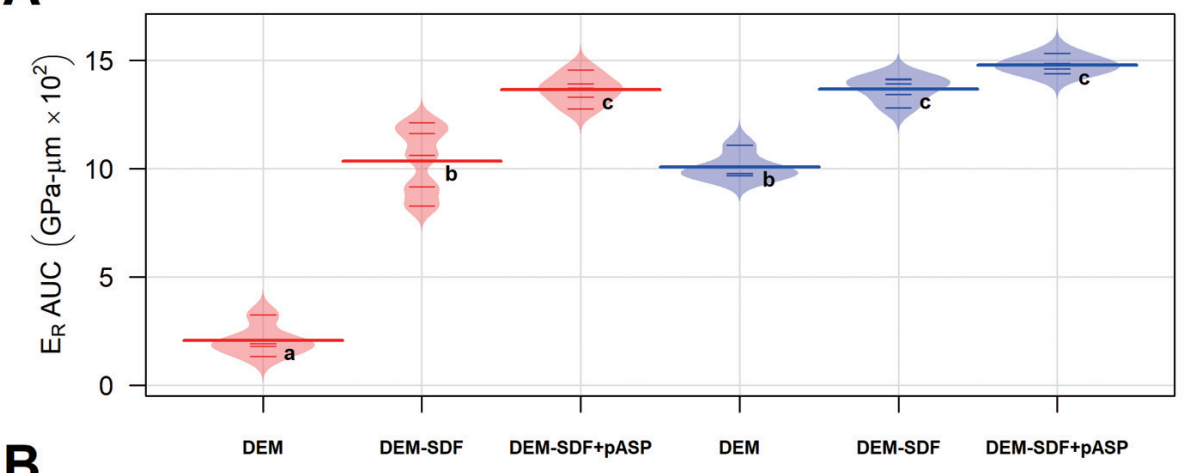

B

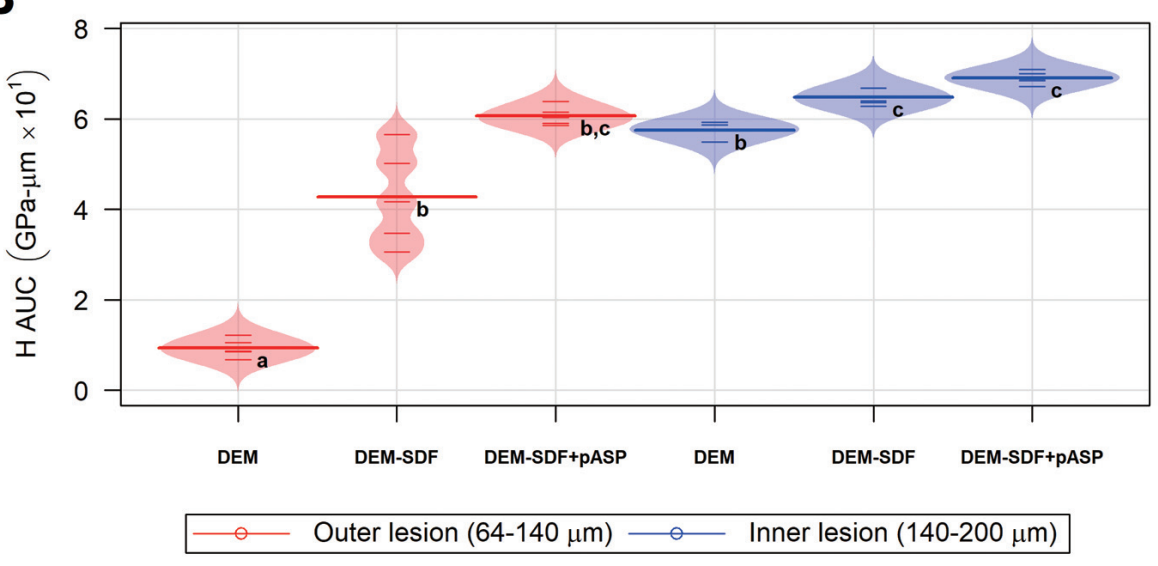

Fig. 4 Distribution and mean area under curve (AUC) by treatment and depth for (A) elastic modulus, $\mathrm{E}_{\mathrm{R}}$, and (B) Nanohardness, H. Means designated with the different small letters indicate significant differences between groups, using mixed effects models and Tukey's adjustment for multiple comparisons (*adj $p<0.01)$. Mean $\pm \mathrm{SD} ; n=5$

about $140-168 \mu \mathrm{m}$. SDF containing pASP resulted in an enhancement of $\mathrm{E}_{\mathrm{R}}$ and $\mathrm{H}$ compared to SDF alone; these showed similar upward sloped regions to $96 \mu \mathrm{m}$, then split where SDF alone dropped while SDF containing pASP continued at a modest upward slope until reaching values of normal dentin at $144 \mu \mathrm{m}$.

Figure 4 shows the results of statistical comparisons between groups in areas under the data curves (AUC) from 64-140 $\mu \mathrm{m}$ (outer lesion) and 140-200 $\mu \mathrm{m}$ (inner lesion) depths. For the mean reduced elastic modulus AUC, DEM was less than DEM-SDF and DEMSDF+pASP in both respective lesion depths (all adj $p<0.001)$. DEM-SDF+pASP was greater than DEM-SDF in the outer lesion (adj $p<0.001$ ) but not conclusive in the inner lesion (adj $p=0.39$ ). For the mean nanohardness AUC, DEM was less than DEM-SDF and DEMSDF+pASP in both respective lesion depths (all adj $p<0.001)$. DEM-SDF+pASP was greater than DEM-SDF in the outer lesion (adj $p=0.002$ ) but only marginally significant in the inner lesion (adj $p=0.08$ ).

\section{DISCUSSION}

This study sought to gain insights into the role of enhanced SDF therapy leading to caries arrest and nanomechanical recovery of demineralized dentin lesions. A reduction in the mechanical properties of dental calcified tissue is one of the basic indications of the caries process, and reversing or stopping this reduction is highly significant for successful clinical management. The current study shows the nanomechanical properties of artificial caries dentin lesions and SDF-treated lesions measured under wet conditions. The values measured under hydrated conditions are assumed to be closer to the in vivo conditions, as dentin is generally wet in the oral environment and collagenous tissues are much softer when wet ${ }^{22)}$. The use of nanoindentation enables automatic recording and analysis on changes in $\mathrm{E}_{R}$ and $\mathrm{H}$ caused by the demineralizing process and SDF treatment in dentin.

The changes in $\mathrm{E}_{\mathrm{R}}$ and $\mathrm{H}$ of hydrated artificial caries specimens prepared using an acetate buffer $(\mathrm{pH} 5)$ that produces a sloped mineral profile similar to natural lesions were evaluated (Fig. 3), although our artificial lesions had a larger and more pronounced outer zone of very low nanomechanical properties as compared to the natural caries previously studied ${ }^{1,16,17)}$. In the treatment group, Fig. 3 shows SDF alone can penetrate 
the full thickness of demineralized dentin with further penetration into the underlying sound dentin. However, the $E_{R}$ and $H$ values varied with location in the lesion. The result of the current study was different from the ex vivo studies which investigated the collected exfoliated primary teeth from the SDF clinical trials and found that a hardened and highly mineralized zone was formed in the outermost area of an SDF-treated carious lesion ${ }^{5)}$. In that study, SDF was applied into the natural lesion in oral cavity for 30 months and the analysis was performed on the teeth after extraction. On the other hand, in the current study we used artificial caries lesions. Artificial lesions offer significant advantages over natural lesions since they are reproducible, and control lesions can be evaluated as well as the nanomechanically recovered lesions. In addition, natural dentin caries are geometrically complex with variations in width, depth, severity, permeability and color, making it difficult to find many similar lesions for in vitro studies. The use of an artificial caries-like lesion model with $140 \mu \mathrm{m}$ lesions depth allowed for evaluation of SDF penetration, distribution, and nanomechanical recovery changes across a sufficiently wide range of depth. It should be noted that the SDF-treated artificial caries lesions were not subjected to remineralization solution in the current study. We hypothesized that the hardening in this current study is due to reaction with silver ${ }^{23)}$, rather than classic fluoride-mediated remineralization. Further work is needed to focus on exploring the possibility of remineralizing while arresting caries.

Figures $2 \mathrm{~B}$ and $\mathrm{C}$ showed brown-black pigmentation suggesting arrested caries lesions due to the formation of a silver phosphate ${ }^{23)}$. It is plausible that silver can be incorporated into the crystal structure of hydroxyapatite and produce silver-containing hydroxyapatite ${ }^{24)}$. The fact that black stain penetrated and extended past the lesion depth into normal dentin suggests silver deposition into demineralized dentin and normal dentin (Figs. 2B and C). Interestingly, integrating the PILP process enhanced the SDF therapy (Figs. 3 and 4). The depth of penetration, distribution and extent of arrested lesions matches that of the structures observed as visible coal-black striated stains from light microscope imaging (Fig. 2C). However, the precise mechanism of action of the SDF combined with pASP is not completely understood. A possible explanation for this could be due to its ability to chelate metal ions such as silver ions ${ }^{25)}$, it may stabilize the SDF ions in solution and enhances its therapy, perhaps by promoting the Gibbs-Donnan effect as described for collagen infiltration ${ }^{26)}$.

As noted, our the SDF+pASP solution was stable, however, at this point it is not clear what concentration of pASP will be optimal. Previous studies found that only $0.1 \mathrm{mg} / \mathrm{mL}$ pASP were sufficient to remineralize artificial lesions in dentin when PILP was applied in solution, but those studies used between 40 and 200 $\mathrm{mL}$ of PILP-solution ${ }^{27,28)}$. Here only about $22 \mu \mathrm{L}$ (1-drop SDF solution) are applied once without replenishment of PILP-solution. Hence this approach tried to maximize the pASP delivery in a single SDF application.
In conclusion, this nanoindentation study provided data which suggests that integration of the PILP-process in an SDF caries treatment is feasible and can promote nanomechanical recovery of demineralized dentin. These new observations hint at mechanistic explanations for the first clinical method to harden caries dentin besides remineralization. The use of this enhanced SDF therapy could improve current approaches in minimally-invasive dentistry by adding a reliable method to repair dentin damaged by the caries process, and may further promote the ongoing paradigm shift in dentistry.

\section{ACKNOWLEDGMENTS}

This study was funded by Strategic Research Fund award (Number: 501-504) of the A.T. Still University. The authors declare no potential conflicts of interest with respect to the authorship and/or publication of this article. The authors thank late Dr. Yung-Ching Chien for helpful discussions regarding the artificial caries model and demineralization kinetics of the acetate buffer system.

\section{REFERENCES}

1) Bacino M, Girn V, Nurrohman H, Saeki K, Marshall SJ, Gower L, et al. Integrating the PILP-mineralization process into a restorative dental treatment. Dent Mater 2019; 35: 5363.

2) Tersariol IL, Geraldeli S, Minciotti CL, Nascimento FD, Paakkonen V, Martins MT, et al. Cysteine cathepsins in human dentin-pulp complex. J Endod 2010; 36: 475-481.

3) Tjaderhane L, Nascimento FD, Breschi L, Mazzoni A, Tersariol IL, Geraldeli S, et al. Optimizing dentin bond durability: control of collagen degradation by matrix metalloproteinases and cysteine cathepsins. Dent Mater 2013; 29: 116-135.

4) Rosenblatt A, Stamford TC, Niederman R. Silver diamine fluoride: a caries "silver-fluoride bullet". J Dent Res 2009; 88: 116-125.

5) Chu CH, Lo EC. Microhardness of dentine in primary teeth after topical fluoride applications. J Dent 2008; 36: 387-391.

6) Burwell AK, Thula-Mata T, Gower LB, Habelitz S, Kurylo $\mathrm{M}, \mathrm{Ho}$ SP, et al. Functional remineralization of dentin lesions using polymer-induced liquid-precursor process. PLoS One 2012; 7: e38852.

7) Nurrohman H, Carneiro KMM, Hellgeth J, Saeki K, Marshall $\mathrm{SJ}$, Marshall GW, et al. The role of protease inhibitors on the remineralization of demineralized dentin using the PILP method. PLoS One 2017; 12: e0188277.

8) Olszta MJ, Cheng X, Jee SS, Kumar R, Kim YY, Kaufman MJ, et al. Bone structure and formation: A new perspective. Mater Scie Eng R Rep 2007; 58: 77-116.

9) Nurrohman H, Saeki K, Carneiro K, Chien YC, Djomehri S, Ho SP, et al. Repair of dentin defects from DSPP knockout mice by PILP mineralization. J Mater Res 2016; 31: 321-327.

10) Gower LB. Biomimetic model systems for investigating the amorphous precursor pathway and its role in biomineralization. Chem Rev 2008; 108: 4551-4627.

11) Nudelman F, Pieterse K, George A, Bomans PH, Friedrich H, Brylka LJ, et al. The role of collagen in bone apatite formation in the presence of hydroxyapatite nucleation inhibitors. Nat Mater 2010; 9: 1004-1009.

12) Saxena N, Cremer MA, Dolling ES, Nurrohman H, Habelitz S, Marshall GW, et al. Influence of fluoride on the mineralization of collagen via the polymer-induced liquid-precursor (PILP) 
process. Dent Mater 2018; 34: 1378-1390.

13) Habelitz S, Marshall GW Jr, Balooch M, Marshall SJ. Nanoindentation and storage of teeth. J Biomech 2002; 35: 995-998.

14) Saeki K, Chien YC, Nonomura G, Chin AF, Habelitz S, Gower LB, et al. Recovery after PILP remineralization of dentin lesions created with two cariogenic acids. Arch Oral Biol 2017; 82: 194-202.

15) Chien YC, Burwell AK, Saeki K, Fernandez-Martinez A, Pugach MK, Nonomura G, et al. Distinct decalcification process of dentin by different cariogenic organic acids: Kinetics, ultrastructure and mechanical properties. Arch Oral Biol 2016; 63: 93-105.

16) Pugach MK, Strother J, Darling CL, Fried D, Gansky SA, Marshall SJ, et al. Dentin caries zones: mineral, structure, and properties. J Dent Res 2009; 88: 71-76.

17) Zheng L, Hilton JF, Habelitz S, Marshall SJ, Marshall GW. Dentin caries activity status related to hardness and elasticity. Eur J Oral Sci 2003; 111: 243-252.

18) Han M, Li QL, Cao Y, Fang H, Xia R, Zhang ZH. In vivo remineralization of dentin using an agarose hydrogel biomimetic mineralization system. Sci Rep 2017; 7: 41955.

19) Fitzmaurice GM, Laird NM, Ware JH. Applied longitudinal analysis. Hoboken, NJ: Wiley; 2011.

20) Muggeo VMR. Segmented: An R package to fit regression models with broken-line relationships. $\mathrm{R}$ News 2008; 8: 2025.

21) Marshall GW Jr, Wu-Magidi IC, Watanabe LG, Inai N, Balooch M, Kinney JH, et al. Effect of citric acid concentration on dentin demineralization, dehydration, and rehydration: atomic force microscopy study. J Biomed Mater Res 1998; 42: 500-507.

22) Bertassoni LE, Habelitz S, Kinney JH, Marshall SJ, Marshall GW Jr. Biomechanical perspective on the remineralization of dentin. Caries Res 2009; 43: 70-77.

23) Mei ML, Lo ECM, Chu CH. Arresting dentine caries with silver diamine fluoride: What's behind it? J Dent Res 2018; 97: 751-758.

24) Chen W, Liu Y, Courtney HS, Bettenga M, Agrawal CM, Bumgardner JD, et al. In vitro anti-bacterial and biological properties of magnetron co-sputtered silver-containing hydroxyapatite coating. Biomaterials 2006; 27: 5512-5517.

25) Low KC, Wheeler AP, Koskan LP. Commercial poly(aspartic acid) and its uses: performance with environmental acceptance 1996; 99-111.

26) Niu LN, Jee SE, Jiao K, Tonggu L, Li M, Wang L, et al. Collagen intrafibrillar mineralization as a result of the balance between osmotic equilibrium and electroneutrality. Nat Mater 2017; 16: 370-378.

27) Thula TT, Svedlund F, Rodriguez DE, Podschun J, Pendi L, Gower LB. Mimicking the nanostructure of bone: comparison of polymeric process-directing agents. Polymers (Basel) 2011; 3: $10-35$.

28) Jee SS, Thula TT, Gower LB. Development of bone-like composites via the polymer-induced liquid-precursor (PILP) process. Part 1: influence of polymer molecular weight. Acta Biomater 2010; 6: 3676-3686. 